\title{
Reducing selection bias in a cluster randomized trial in West African villages
}

\author{
Sally M Kerry ${ }^{a}$, Francesco P Cappuccio ${ }^{a}$, Lynsey Emmett ${ }^{a}$, Jacob Plange-Rhule ${ }^{b}$ \\ and John B Eastwood
}

\begin{abstract}
Selection bias in cluster randomized trials may threaten the validity of the results. This bias may occur either at the level of the cluster or of the individual. We describe measures for maintaining comparability of intervention groups in a cluster randomized trial of a health education package to reduce dietary salt. The setting was 12 villages of the Ashanti region of Ghana. In total, 1896 villagers between 40 and 75 years of age were selected to take part in the trial using stratified random sampling, based on age and sex. Following individuals' consent and baseline measurements in a pair of villages, villages were randomized to intervention or control arms, stratified for locality (semi-urban or rural). Primary outcomes of the trial were reduction in 24-hour urinary sodium and blood pressure. Of the villagers, 1013 individuals agreed to take part, with a response rate of $53 \%$. The groups were comparable with respect to mean (SD) systolic and diastolic blood pressure (125/74 $(27 / 14) \mathrm{mmHg}$ versus $126 / 75(25 / 14) \mathrm{mmHg}$ ) and other outcomes. In conclusion, in this study blind recruitment, aided by randomization in small blocks, and stratified random sampling of the subjects within the clusters helped to ensure comparability of intervention groups, which is vital for the validity of the trial results. Clinical Trials 2005; 2: 125-129. www.SCTjournal.com
\end{abstract}

\section{Introduction}

Cluster randomized trials are often used to evaluate health initiatives in developing countries where individual randomization is difficult or impossible. Recently, the risk of selection bias associated with this design [1] and the inadequate analyses and reporting of such trials [2] have been highlighted as a potentially serious threat to the validity of trial results. A recent review [3] showed that while there was little evidence of imbalance at the cluster level, 14 out of 36 trials showed evidence of susceptibility to bias at the level of the individual. Careful planning and execution of such trials, giving particular attention to the way individuals are recruited, can reduce these biases.

Health education in Ghana normally takes place via village meetings and small groups in the villages, thus making a cluster trial the most appropriate design. Here we present a detailed account of steps taken to ensure comparability of intervention groups in a cluster randomized trial in Ghana of a health education package to reduce salt intake and thereby reduce blood pressure. We stratified both at cluster and individual level and recruited subjects blind to their intervention group. The baseline characteristics of the two intervention groups have been compared to evaluate recruitment bias. We also discuss some of the problems encountered in running a trial in a developing country.

\section{The stroke prevention study}

Twelve villages (six rural, six semi-urban), who had little day-to-day contact with each other, were invited to take part in the study. All were within a $40 \mathrm{~km}$ radius of Kumasi, the second largest city in Ghana. Representatives of the local study team (doctors, nurses and clerks from Komfo Anokye

\footnotetext{
aDepartment of Community Health Sciences, St. George's Hospital Medical School, Cranmer Terrace, London SW17 0RE, UK, 'bepartment of Medicine, Komfo Anokye Teaching Hospital, Kumasi, Ghana, 'Department of Renal Medicine, St. George's Hospital Medical School, Cranmer Terrace, London SW17 ORE, UK

Author for Correspondence: Sally M Kerry, Department of Community Health Sciences, St George's Hospital Medical School, Cranmer Terrace, London, SW17 ORE, UK
} 
Teaching Hospital in Kumasi and the local community health workers) met with the chiefs and elders of each village to explain the study and gain their permission to carry out the census and to set up a local field station, usually in the village school or church. A household survey was then carried out identifying 2743 villagers aged 40-75 years [4]. Between 95 and 250 subjects from each village were selected using stratified random sampling. The strata were defined by age $(40-49,50-59,60-69$, 70-75) and gender.

The census showed that some villages had a greater proportion of men and of villagers over 50 years of age. So that the two intervention groups were balanced with respect to age and sex we used stratified random sampling so that the proportion of villagers selected in each age and sex category was the same in each village, and matched the overall proportion in that age and sex category. In this way the age and sex distribution of the invited sample within each village matched the age and sex distribution of the twelve villages taken as a whole.

In each village, recruitment was carried out on three mornings within a two-week period. The local team explained the study to all selected villagers as a group and then individually to each person. A written information sheet was prepared in the local language, Twi, and given to those who could read. It was also used to guide the field workers in explaining the study to all participants. Participants gave consent by signing the consent form, also written in Twi, or gave a thumb print if unable to sign their name. All those who consented were interviewed, had their blood pressure and a blood sample taken and were asked to collect urine for two 24-hour periods. People with serious mental or physical illness, and pregnant or lactating women were excluded. Individuals with blood pressure $\geq 200 \mathrm{mmHg}$ systolic and/or $\geq 120 \mathrm{mmHg}$ diastolic were referred to hospital for treatment and excluded from the study.

Allocation of villages to intervention and control groups took place after recruitment of participants. Villages were randomized in blocks of two, and stratified for locality (semi-urban or rural) by an independent statistician. Thus the intervention could begin in the first two villages while subjects in the second two were being recruited.

All villagers received health education, delivered to the entire community, daily for the first week then weekly for the rest of the first month. There were whole village and small group meetings and household visits. Each session lasted 1.5 hours. Session involved the use of flip charts with pictures on the front and words on the back to guide the field worker. Flipcharts were identical for both groups, covering a range of topics such as pregnancy and childbirth, malaria, worms, anaemia and dental hygiene except that the intervention group had an extra section about the relationship between hypertension and stroke, the role of salt and how to reduce the amount of salt consumed. It was emphasized to the field workers they were not to mention salt in the control group.

The study protocol was approved by the Local Research Ethics Committee in London, as well as the Committee on Human Research Publication and Ethics, School of Medical Sciences, Kwame Nkrumah University of Science and Technology, Kumasi, Ghana.

\section{Sample size of the trial and statistical analysis}

The main outcomes of the trial were the fall in systolic blood pressure over six months and the fall in 24-hour urinary sodium. A sample size of 70 participants from each village completing the trial would allow a fall in systolic blood pressure of $4.8 \mathrm{mmHg}$ to be detected with $90 \%$ power, using a $5 \%$ significance level, assuming the standard deviation of the fall in blood pressure was $12.6 \mathrm{mmHg}$ and the intra-cluster correlation coefficient was 0.02 [5].

Initially 95 subjects were invited from each village to allow for a $25 \%$ refusal and attrition rate. As response rate in the first four villages was lower than anticipated, more subjects were recruited in the remaining villages to obtain sufficient subjects overall and to allow for a greater refusal rate. The original design was for each village to contribute the same number of subjects. However increasing the number of subjects in the smaller villages, while keeping the same age and sex balance in all villages, was not possible, so extra subjects were only recruited from the larger villages, keeping the imbalance in cluster sizes to a minimum [6]. Between 95 and 250 were invited depending on the size of the village. It was estimated the study would be able to detect a reduction of $20 \%$ in urinary sodium from $90 \mathrm{mmol} /$ day to $72 \mathrm{mmol} /$ day with $90 \%$ power assuming the same intra cluster correlation coefficient (0.02) as for blood pressure.

To evaluate measures for maintaining comparability of trial arms we looked at baseline characteristics of the intervention groups. As we had stratified by locality (semi-urban or rural) we also compared the two, to assess the effect of this on blood pressure and salt intake. All analyses were carried out in Stata [7] and 95\% confidence intervals (CI) were adjusted for clustering by village. For continuous variables (blood pressure, age, urinary sodium) regression was carried out using intervention groups and locality as a fixed effects and robust standard errors (Huber-White) clustering on 
village. For binary outcomes the per cent within each village was calculated and analysis carried out on these summary statistics, weighting for cluster size. The percentage estimate is the same as would be obtained from a simple percentage ignoring the clustering but the confidence intervals calculated in this way allow for clustering. The 95\% confidence intervals were calculated by boot strapping as the individual proportions were not normally distributed. The analysis has also been undertaken blind to the allocation so intervention groups are labelled Group 1 and Group 2.

\section{Response rate}

The overall response rate was 53\% (1013/1896) but this varied considerably between the villages (range $40 \%$ to $88 \%$ ). Response rates were higher in women than men; 58\% $(628 / 1088)$ versus $48 \%(385 / 808)$ and responders were 2.0 (95\% CI, 0.8 to 3.1 ) years older than nonresponders. In rural villages men and women responded similarly (57\% versus $60 \%$; difference $-3 \%$, [-21 to 20]) but in the semiurban villages men were less likely to respond (41\% versus $56 \%$; difference $-15 \%$, [-26 to -4$]$ ).

The response rate was lower than expected but this is likely to be unrelated to the intervention itself. First, there was a delay of up to 18 months between the household survey and starting the fieldwork in some villages. Villagers did not always remember the initial visit where the study had been explained and the chiefs and elders had agreed to the study taking place and some may have died or moved away. Secondly, we took a blood sample to measure factors related to cardiovascular disease but in some villages rumours spread that the blood was to be tested for HIV infection. In Ghana a positive HIV test carries great stigma for the whole family. Thirdly, while the time of data collection, 6 a.m. onwards, suited those working on their farms locally, others would have left for work at this time. This is likely to account for the lower response rate amongst men in semi-urban villages.

\section{Stratification at cluster level}

As in other studies [8-10], subjects from rural villages had lower blood pressure (Table 1). They were also more likely to add salt to their food at the table although there was no significant difference in urinary sodium (Table 1). Stratifying by locality thus removes a potentially important confounder, and may also increase the power of the study. In this study adjusting for locality reduced the width of the confidence intervals for blood pressure between intervention groups by around $50 \%$, indicating that locality (semi-urban or rural) accounts for a substantial part of the variability between villages (Table 2). Todd et al. found in three cluster randomized trials to reduce HIV incidence that stratification of heterogeneous communities prior to randomization reduced the between community variability and increased the power of the trials [11].

\section{Stratification at individual level}

While many studies have used stratification at cluster level this study also used stratification at individual level. The household survey showed some differences between the villages in age and sex distribution, both factors that might influence the success of the intervention. Rather than try to balance the age/sex at the cluster level using mean age and percentage females, we stratified at the individual level by age and sex so that participants from each village would have the same age/sex structure.

Table 1 Baseline characteristics of 1013 villagers in six rural and six semi-urban villages

\begin{tabular}{|c|c|c|c|}
\hline & \multicolumn{2}{|c|}{ Locality } & \multirow[b]{2}{*}{$\begin{array}{l}\text { Difference }{ }^{\mathrm{b}} \text { between } \\
\text { locality R - SU }(95 \% \mathrm{Cl})\end{array}$} \\
\hline & $\begin{array}{l}\text { Rural villages (R) } \\
(n=481) \\
\text { Mean }(95 \% \mathrm{Cl})\end{array}$ & $\begin{array}{l}\text { Semi-urban villages (SU) } \\
(n=532) \\
\text { Mean }(95 \% \mathrm{Cl})\end{array}$ & \\
\hline Response rate $^{\mathrm{a}}(\%)$ & $59(48$ to 75$)$ & $49(42$ to 56$)$ & $10(-4$ to 27$)$ \\
\hline Age (years) & $54.5(53.5$ to 55.6$)$ & $54.9(54.1$ to 55.7$)$ & $-0.4(-1.6$ to 0.9$)$ \\
\hline Male $(\%)$ & $40(36$ to 44$)$ & $36(33$ to 40$)$ & $3(-2$ to 8$)$ \\
\hline Systolic blood pressure $(\mathrm{mmHg})$ & $121.5(119.4$ to 123.6$)$ & $129.2(127.2$ to 131.3$)$ & $-7.7(-10.7$ to -4.8$)$ \\
\hline Diastolic blood pressure $(\mathrm{mmHg})$ & $72.3(71.0$ to 73.6$)$ & $76.2(75.3$ to 77.2$)$ & $-3.9(-5.5$ to -2.3$)$ \\
\hline Urinary sodium $(\mathrm{mmol} / 24 \mathrm{~h})$ & 99 (90 to 108$)$ & $103(95$ to 111$)$ & $-4(-16$ to 8$)$ \\
\hline Sodium/creatinine ratio & $12.6(11.2$ to 14.0$)$ & $12.4(11.5$ to 13.5$)$ & $0.2(-1.6$ to 1.9$)$ \\
\hline Salt added at table (\%) & $59(52$ to 69$)$ & $45(40$ to 50$)$ & $14(5$ to 25$)$ \\
\hline
\end{tabular}

${ }^{a} 1013$ responders out of 1896 invited.

${ }^{\mathrm{b}}$ Difference is difference in means or difference in percentages. 
Table 2 Baseline characteristics of 1013 villagers comparing the two intervention groups

\begin{tabular}{|c|c|c|c|c|}
\hline & \multicolumn{2}{|c|}{ Intervention group } & \multirow[b]{2}{*}{$\begin{array}{l}\text { Difference }^{\mathrm{b}} \\
\text { Group } 1-\text { Group } 2 \\
(95 \% \mathrm{Cl})\end{array}$} & \multirow[b]{2}{*}{$\begin{array}{l}\text { Difference }{ }^{b} \\
\text { adjusted for locality } \\
(95 \% \mathrm{CI})\end{array}$} \\
\hline & $\begin{array}{l}\text { Group } 1 \\
(n=491) \text { Mean } \\
(95 \% \mathrm{Cl})\end{array}$ & $\begin{array}{l}\text { Group } 2 \\
(n=522) \text { Mean } \\
(95 \% \mathrm{Cl})\end{array}$ & & \\
\hline Response rate ${ }^{a}(\%)$ & $51(42$ to 63$)$ & $56(48$ to 71$)$ & $-6(-21$ to 9$)$ & $-6(-20$ to 11$)$ \\
\hline Age (years) & $55.2(54.9$ to 55.5$)$ & $54.3(53.2$ to 55.4$)$ & $0.9(-0.2$ to 2.0$)$ & $0.9(-0.2$ to 2.0$)$ \\
\hline Male (\%) & 38 (34 to 43$)$ & 38 (35 to 41$)$ & $0(-6$ to 5$)$ & $00(-6$ to 5$)$ \\
\hline $\begin{array}{l}\text { Systolic blood } \\
\text { pressure }(\mathrm{mmHg})\end{array}$ & 124.6 (120.2 to 129.0$)$ & $126.4(122.4$ to 130.4$)$ & -1.8 ( -7.7 to 4.3$)$ & $-1.0(-3.8$ to 1.7$)$ \\
\hline $\begin{array}{l}\text { Diastolic blood } \\
\text { pressure }(\mathrm{mmHg})\end{array}$ & 73.7 (71.3 to 76.2 ) & 75.0 (73.3 to 76.7$)$ & $-1.3(-4.3$ to 1.7$)$ & $-0.9(-2.5$ to 0.6$)$ \\
\hline $\begin{array}{l}\text { Urinary sodium } \\
\quad(\mathrm{mmol} / 24 \mathrm{~h})\end{array}$ & 103 (92 to 113 ) & 100 (93 to 107$)$ & $3(-10$ to 15$)$ & $3(-9$ to 16$)$ \\
\hline $\begin{array}{l}\text { Sodium/creatinine } \\
\text { ratio }\end{array}$ & $12.7(11.4$ to 14.0$)$ & 12.4 (11.3 to 13.5$)$ & $0.3(-1.4$ to 2.0$)$ & $0.3(-1.5$ to 2.0$)$ \\
\hline $\begin{array}{l}\text { Salt added } \\
\text { at table (\%) }\end{array}$ & 54 (48 to 63 ) & 50 (42 to 62$)$ & $4(-10$ to 16$)$ & $3(-9$ to 12$)$ \\
\hline
\end{tabular}

${ }^{\mathrm{a}} 1013$ responders out of 1896 invited.

${ }^{b}$ Difference is difference in means or differences in percentages.

\section{Blind recruitment}

The low response rate introduces the possibility of recruitment bias, thus making blind recruitment more important. In this case both the field workers and the subjects did not know to which intervention group the village would be allocated until after all the subjects had been recruited. There are several features of this study that made blind recruitment a possibility. First, we were able to identify subjects in advance. Secondly, we did not need to train staff from the village to carry out the intervention after randomization. Thirdly, we were able to recruit all subjects from a cluster in a short space of time so that there was no overlap between recruiting individuals and implementing the education package. Fourthly, we used the same information sheet in both groups. In our study we did not mention salt specifically in the information sheet but all subjects were asked to attend health education sessions and that it was "possible that changing your diet may reduce your blood pressure". This is similar to the approach adopted by Little and colleagues in a trial of prescribing strategies for sore throats [12], where patients consented to take part in "a study looking at how quickly sore throats settle", although in this case the trial was individually randomized.

\section{Block randomization}

We employed a small block randomization using blocks of size 2 and allocation revealed when subject recruitment had been completed in the whole block. Thus the timing of the intervention would be balanced in each group and the field workers would not know the allocation of the last two villages when recruiting participants. After participants had been recruited from a pair of villages the allocation was revealed so that the education could begin.

\section{Comparability of the intervention groups}

Response rates and baseline characteristics were similar in the two intervention groups (Table 2) although some of the confidence intervals were wide because of large variability between clusters. Thus, despite the suboptimal recruitment rate there is no evidence of selection bias in the baseline characteristics of the participants.

\section{Conclusions}

While stratification at cluster level has been used in many trials, as far as we are aware this is the first cluster trial to use stratification at the level of the individual and to randomize in small blocks to facilitate blind recruitment of subjects. These steps have helped to ensure comparability of intervention groups, which is vital for the validity of the trial results.

\section{Acknowledgements}

The study was funded by The Wellcome Trust (Grants 060415/Z/00/Z and 069500/Z/02/Z). FPC is a member of the St. George's Cardiovascular Research Group. 


\section{References}

1. Medical Research Council. Cluster randomised trials: Methodological and ethical considerations. MRC clinical trials series. London: Medical Research Council, 2002.

2. Isaakidis P, Ioannidis JPA. Evaluation of cluster randomised controlled trials in sub-Saharan Africa. Am J Epidemiol 2003; 158: 921-26.

3. Puffer S, Torgerson D, Watson J. Evidence for risk of bias in cluster randomised trials: review of recent trials published in three general medical journals. BMJ 2003; 327: 785-89.

4. Plange-Rhule J, Cappuccio FP, Emmett L. et al. A community study of health promotion in rural West Africa: details of a household survey and population census. QJM 2002; 95: 445-50.

5. Steptoe A, Doherty S, Rink E, Kerry S, Kendrick T, Hilton S. Behavioural counselling in general practice for the promotion of healthy behaviour among adults at increased risk of coronary heart disease: randomised trial. BMJ 1999; 319: 943-47.

6. Kerry SM, Bland JM. Unequal cluster sizes for trials in UK General Practice: implications for sample size calculations. Stat Med 2001; 20: 377-90.
7. Stata Corporation. StataCorp 2001. Stata Statistical Software: Release 7.0. College Station TX: Stata Corporation, 2001.

8. Poulter N, Khaw KT, Mugambi M, Peart WS, Rose G, Sever P. Blood pressure patterns in relation to age, weight and urinary electrolytes in three Kenyan communities. Trans R Soc Tropical Med Hygiene 1985; 79: 389-82.

9. Sever P, Gordon D, Peart WS, Beighton P. Blood pressure and its correlates in urban and tribal Africa. Lancet 1980; ii: 60-64.

10. Simmons D, Barbour G, Congleton J, Levy J, Meacher P, Saul H, Sowerby T. Blood pressure and salt intake in Malawi: an urban rural study. J Epidemiol Commun Health 1986; 40: 188-92.

11. Todd J, Carpenter $\mathbf{L}$, Li X, Nakiyingi, Gray $\mathbf{R}$, Hayes R. The effects of alternative study designs on the power of community randomised trials: evidence from three studies of human immunodeficiency virus prevention in East Africa. Int I Epidemiol 2003; 32: 755-62.

12. Little P, Williamson I, Warren G, Gould $\mathbf{C}$, Gantley M, Kinmonth AL. Open randomised trial of prescribing strategies for sore throat. BMJ 1997; 314: $722-27$. 